\title{
Hereditary Hemorrhagic Telangiectasia: A Genetic Disorder with Oral Manifestations
}

\author{
${ }^{1}$ Andrea Ballini, ${ }^{2}$ Stefania Cantore, ${ }^{3}$ Apollonia Desiate
}

\begin{abstract}
The case of a 74-year-old man who was diagnosed as having hereditary hemorrhagic telangiectasia $(\mathrm{HHT})$, with telangiectasies localized in oral district is presented. This condition is an autosomal dominant mucocutaneous and visceral fibrovascular dysplasia in which telangiectasia, arteriovenous malformations and aneurysms may be widely distributed throughout the cardiovascular system. It is usually recognized as a 'triad' of telangiectasia, recurrent epistaxis and a family history of the disorder. The nature of the practice of dentistry necessitates a broad understanding of the systemic diseases reflected in the oral cavity. Hereditary hemorrhagic telangiectasia is one such disease.
\end{abstract}

Keywords: Hereditary hemorrhagic telangiectasia, Dental practice, Activin receptor-like kinase 1.

How to cite this article: Ballini $A$, Cantore $S$, Desiate $A$. Hereditary Hemorrhagic Telangiectasia: A Genetic Disorder with Oral Manifestations. Int J Experiment Dent Sci 2014; 3(1): 49-52.

Source of support: Nil

Conflict of interest: None declared

\section{INTRODUCTION}

Hereditary hemorrhagic telangiectasia (HHT), also known as Osler-Weber-Rendu syndrome, is an autosomal dominant vascular dysplasia with a high degree of penetrance but extremely variable expression. It occurs in approximately 1 in 5000 individuals. ${ }^{1-4}$

Hereditary hemorrhagic telangiectasia is a genetic disorder by definition. It is inherited in an autosomal dominant manner, which means that an affected person carries one abnormal gene with a $50 \%$ chance of passing this gene to offspring. Those with HHT symptoms that have no relatives with the disease may have a new mutation. ${ }^{1,25-8}$ It seems that

\footnotetext{
${ }^{1}$ Investigator, ${ }^{2}$ Lecturer, ${ }^{3}$ Associate Professor

1,2Department of Dental Sciences and Surgery, University of Bari Aldo Moro, Piazza Umberto I, Bari, Italy

${ }^{3}$ Department of Interdisciplinary Medicine, University of Bari Aldo Moro, Piazza Umberto I, Bari, Italy

Corresponding Author: Andrea Ballini, Investigator Department of Dental Sciences and Surgery, University of Bari Aldo Moro, Piazza Umberto I, Bari, Italy, Phone: 00393492432155, e-mail: andrea.ballini@me.com
}

carrying two abnormal copies of the gene is not compatible with life, and hence no homozygotes have been described. ${ }^{1}$

Five genetic types of HHT are recognized. Of these, three have been linked to particular genes, while the two remaining have currently only been associated with a particular locus. More than $80 \%$ of all cases of HHT are due to mutations in either endoglin (ENG) or activin receptor-like kinase 1 (ACVRL1). ${ }^{5,8}$ A total of over 600 different mutations is known. There is likely to be a predominance of either type in particular populations, but the data are conflicting. Mothers against decapentaplegic homolog 4 (MADH4) mutations, which cause colonic polyposis in addition to HHT, comprise about $2 \%$ of disease-causing mutations. Apart from MADH4, it is not clear whether mutations in ENG and ACVRL1 lead to particular symptoms, ${ }^{1}$ although some reports suggest that ENG mutations are more likely to cause lung problems while ACVRL1 mutations may cause more liver problems, ${ }^{2,5}$ and pulmonary hypertension may be a particular problem in people with ACVRL1 mutations. ${ }^{8}$ People with exactly the same mutations may have different nature and severity of symptoms, suggesting that additional genes or other risk factors may determine the rate at which lesions develop; these have not yet been identified. ${ }^{2,8}$

Epistaxis is the most frequent presentation; in fact more than $90 \%$ of cases manifest by the age of $21 .^{7,9,10}$

Telangiectases of the tongue, lips and skin are also common. Gastrointestinal involvement presenting as hemorrhage occurs in approximately $16 \%$ of patients; half of these require transfusion. ${ }^{9-13}$ Additional visceral involvement includes pulmonary, hepatic, and cerebral arteriovenous mal formation (AVM), which have been reported predominantly in adults. ${ }^{13-15}$

Approximately, $20 \%$ of adults with HHT have cerebrovascular malformations. ${ }^{13}$ Most are asymptomatic, but some present with acute headache associated with intra-cranial hemorrhage. The prevalence of cerebrovascular malformations among children with HHT is unknown.

The purpose of this article was to describe a molecularly confirmed case of HHT in a 74-year-old man.

\section{CASE REPORT}

Examination of clinical charting, using accepted published criteria, ${ }^{714}$ confirmed the diagnosis of HHT in these patients. 
The diagnosis was made if the patient met at least three of the following four criteria: epistaxis, telangiectases, visceral lesions, and an appropriate family history. This patient presents all the criteria.

A 74-year-old-male patient, with ACVRL1 mutation (genetic diagnosis), referred to our attention for examination. He presented spontaneous nose bleed from the nasal mucosa. While the first one had only occasional epistaxis, the other one experienced significant bleeds on a daily basis. Both had telangiectases of the face skin and buccal mucosa which developed later than epistaxis in his life and increased in size and number by aging. The lesions were present on the face, lips, tongue, and buccal mucosa (Figs 1 to 3). Sometimes, severe hemorrhages originated from telangiectases of the body of the tongue. There was no family history of bleeding episodes. Routine laboratory studies showed normal values except a decreased serum iron levels.

The mutation was detected by sequencing (Figs 4A and B). Polymerase chain reaction (PCR) products were loaded on an ABI Prism 310 automated sequencer and analyzed using the Genescan Analysis software (Applied Biosystems, Foster City, CA, USA).

\section{DISCUSSION}

Unfortunately, HHT is often difficult to diagnose on the basis of history and physical examination alone, especially in infants and children. The signs and symptoms of HHT are nonspecific and even within families are extremely variable.

The most common feature and typical presenting sign of HHT is recurrent epistaxis. Nosebleeds are common in childhood; however, family members with recurrent epistaxis may also discount them as being normal. Although 80 to $90 \%$ of patients with HHT will demonstrate recurrent epistaxis by 21 years of age, most do not have nosebleeds in the first decade of life. ${ }^{1,2,7}$

Cutaneous manifestations, in the form of telangiectases of the lips, palms, nail beds, tongue, ears, or face, are the next most common disease manifestation. Cutaneous manifestations are unusual in children. They typically present later than epistaxis, in the second or third decade of life. By age 40, most individuals will have visible telangiectases. ${ }^{7,14}$

Visceral involvement includes pulmonary, gastro-intestinal, and cerebral arteriovenous malformations (AVMs), which have been reported predominantly in adults. ${ }^{1-3}$

Visceral involvement, specifically gastrointestinal, does not usually manifest until the fifth or sixth decade. Although rare, there have been reports of infants and children with HHT presenting with visceral involvement more commonly seen in adults. Cases involving the lungs, gastrointestinal tract, and urinary tract have been described, which predated epistaxis or cutaneous lesions in these children.

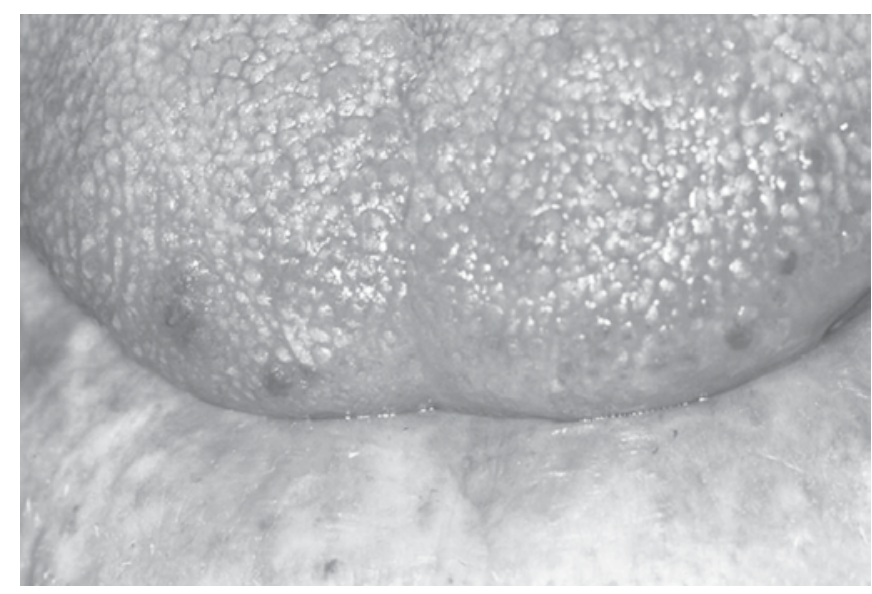

Fig. 1: Telangiectases on the tongue

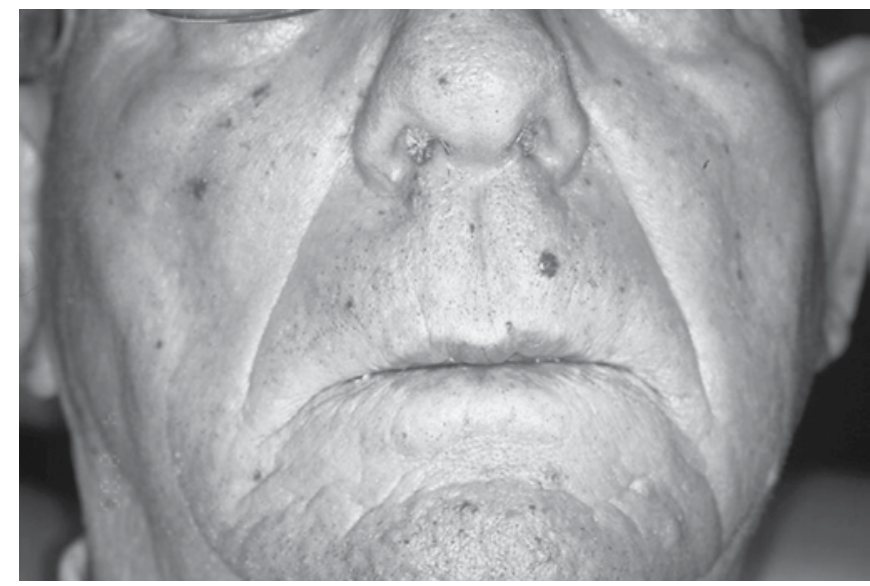

Fig. 2: Multiple facial telangiectases. Large vascular lesions can be seen, consisting of singular dilated vascular loops

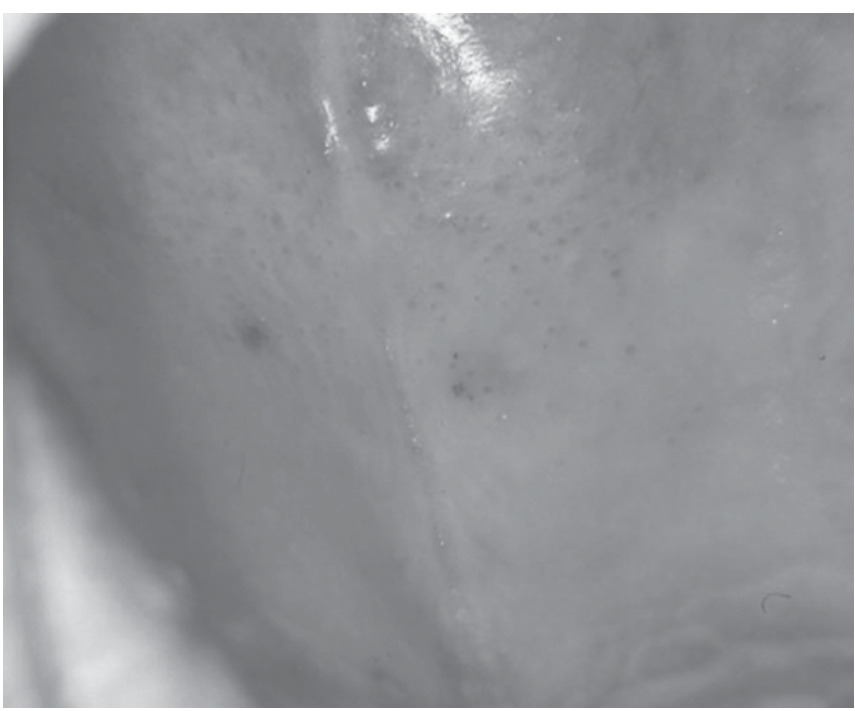

Fig. 3: Multiple patch of telangiectases on the hard palate

The genetic heterogeneity of this disease was shown by several groups, which have demonstrated that at least 3 genes and many different mutations can cause HHT ${ }^{5-8}$ Linkage was originally established in some families to markers on chromosome 9 (9q33-q34). ${ }^{6}$ Subsequent investigation by McAllister et $\mathrm{al}^{5}$ led to the identification of 'endoglin' as the causative gene. Endoglin is a transforming growth factor- 


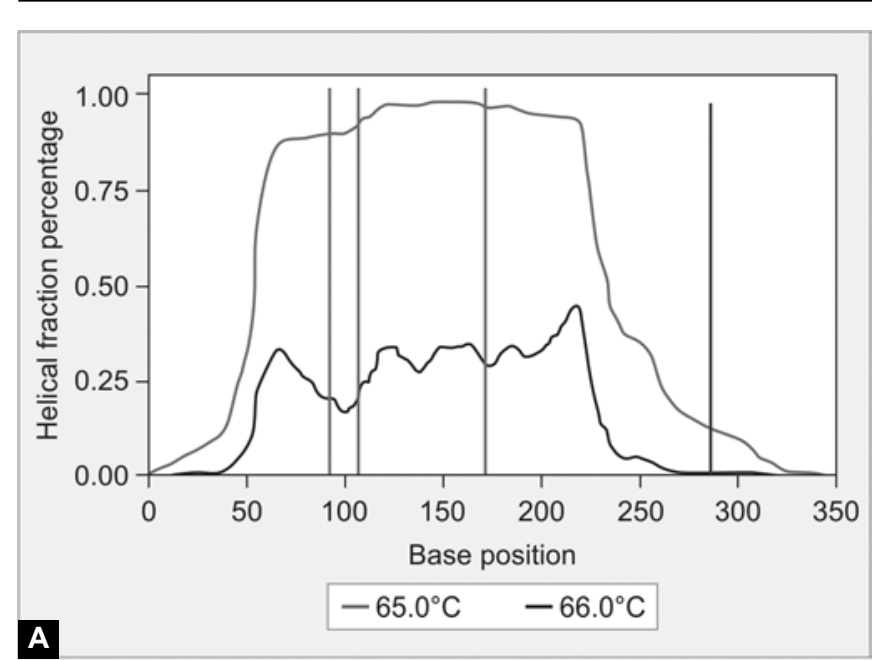

agctgggaccacagtggctgagcttccggtgtgtcttccaggagaccctgtgaagccgtc tcggggcccgctggtgacctgcacgtgtgagagcccacat Tycaaggggcctacctgccg gggggcctggtGcacagtagtgctggtgcgggaggaggggaggcacccccaggaacatc gggctgcgggaacttgcacagggagctctgcagggggcgccccaccgagttcgtcaacca ctactgctgcgacagccacctctgcaaccacaacgtgtccetggtgctggagggtacgtc cagCtgecctagcactccetcccatcttcttggeccetgecctcc

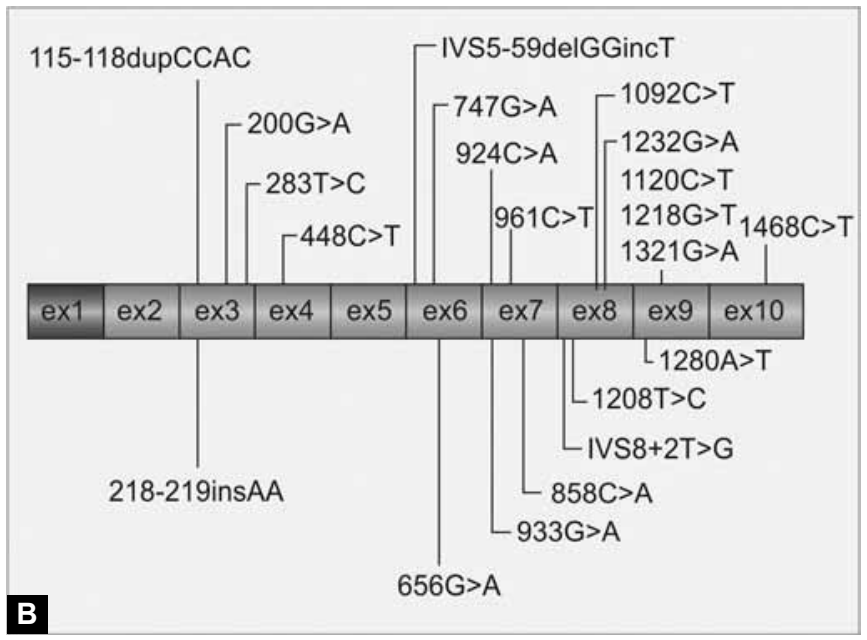

Figs 4A and B: (A) Sequencing: Anealing temperature optimization (B) distribution of the sequence variance identified in ACVRL1 gene

beta (TGF- $\beta$ ) binding protein, which plays an important role in the TGF- $\beta$ receptor complex. These factors regulate differentiation, growth, tissue remodeling, motility, wound repair and programed cell death. ${ }^{1-2}$

Some families have mutations in a different gene. This second locus for HHT is located on chromosome 12 (12q13) and is named ACVRL1. This form of the disease, HHT type 2 , is suspected to have a decreased incidence of pulmonary AVMs, but has been shown to be associated with the same visceral AVMs as HHT type $1 .^{1-2}$

Treatment of HHT is symptomatic (it deals with the symptoms rather than the disease itself), as there is no therapy that stops the development of telangiectasias and AVMs directly. Furthermore, some treatments are applied to prevent the development of common complications. ${ }^{2,7}$ Chronic nosebleeds and digestive tract bleeding can both lead to anemia; if the bleeding itself cannot be completely stopped, the anemia requires treatment with iron supplements. Those who cannot tolerate iron tablets or solutions may require administration of intravenous iron sucrose, and blood transfusion if the anemia is causing severe symptoms that warrant rapid improvement of the blood count. ${ }^{8-10}$

Most treatments used in HHT have been described in adults, and the experience in treating children is more limited. ${ }^{714}$ Women with HHT who get pregnant are at an increased risk of complications, and are observed closely, although the absolute risk is still low $(1 \%){ }^{1}$

\section{CONCLUSION}

In general, HHT diagnosis is essentially clinical, based on macroscopic analyses.

Because molecular analysis is not available on a routine clinical basis, the diagnosis in most families relies on physical examination and history. As we have shown, a routine physical examination and family history may not be sufficient to diagnose HHT in a patient. A detailed and targeted family history may be required. The family history should include questions about recurrent epistaxis, telangiectases, migraines, seizures, internal bleeding, and surgery for vascular malformations. A family history of HHT, especially if a parent is affected, should raise the suspicion of HHT in the child (autosomal dominant inheritance; therefore, $50 \%$ risk of having HHT for each child). We wish to underline the importance of an early screening and regular follow-up of HHT patients to minimise the risk of development of serious sequelae, such as thromboembolic strokes and cerebral abscesses. The differential diagnosis should always include HHT in presence of multiple mucocutaneous telangiectases, paying attention to a patient with prolonged gingival hemorrhage. Antibiotic prophylaxis should be prescribed prior to providing surgical dental treatment to patients with suspected HHT. A relationship between periodontal abscesses in a patient with multiple gingival telangiectases and repeated episodes of septic pulmonary emboli has also been reported. In conclusion, this form of angiodysplasia will often be seen by dental practitioner because of the frequency of maxillofacial involvement. Moreover, since hemorrhage is the most common manifestation, it is also very important to monitor these patients for the development of possible serious complications. The nature of the practice of dentistry necessitates a broad understanding of the systemic diseases reflected in the oral cavity. Hereditary hemorrhagic telangiectasia is one such disease.

\section{ACKNOWLEDGMENTS}

The author AB would like to thank Drs Francesco Spinelli, Gennaro M Lenato and Patrizia Lastella (Section of Medical Genetics) for their contribution in molecular diagnosis. 


\section{REFERENCES}

1. Dupuis-Girod S, Bailly S, Plauchu H. Hereditary hemorrhagic telangiectasia (HHT): from molecular biology to patient care. J Thromb Haemost 2010;8(7):1447-1456.

2. Govani FS, Shovlin CL. Hereditary haemorrhagic telangiectasia: a clinical and scientific review. Eur J Human Genet 2009;17 (7):860-871

3. Fuchizaki U, Miyamori H, Kitagawa S, Kaneko S, Kobayashi K. Hereditary haemorrhagic telangiectasia (Rendu-Osler-Weber disease). Lancet 2003;362(9394):1490-1494.

4. Vincent P, Plauchu H, Hazan J, Fauré S, Weissenbach J, Godet J. A third locus for hereditary hemorrhagic telangiectasia maps to chromosome 12q. Hum Mol Genet 1995;4(5):945-949.

5. McAllister K, Grogg K, Johnson D, Gallione CJ, Baldwin MA, Jackson CE, Helmbold EA, Markel DS, McKinnon WC, Murrell J, et al. Endoglin, a TGF- $\beta$ binding protein of endothelial cells, is the gene for hereditary hemorrhagic telangiectasia type 1. Nat Genet 1994;8(4):345-351.

6. McDonald MT, Papenberg KA, Ghosh S, Glatfelter AA, Biesecker BB, Helmbold EA, Markel DS, Zolotor A, McKinnon WC, Vanderstoep JL, et al. A disease locus for hereditary haemorrhagic telangiectasia maps to chromosome 9q33-34. Nat Genet 1994;6(2):197-204.

7. Faughnan ME, Palda VA, Garcia-Tsao G, Geisthoff UW, McDonald J, Proctor DD, Spears J, Brown DH, Buscarini E, Chesnutt MS, et al. International guidelines for the diagnosis and management of hereditary hemorrhagic telangiectasia. $\mathrm{J}$ Med Genet 2011;48(2):73-87.
8. Johnson DW, Berg JN, Baldwin MA, Gallione CJ, Marondel I, Yoon SJ, Stenzel TT, Speer M, Pericak-Vance MA, Diamond $\mathrm{A}$, et al. Mutations in the activin receptor-like kinase 1 gene in hereditary hemorrhagic telangiectasia type 2 . Nat Genet 1996; 13(2):189-195.

9. Aassar O, Friedman CM, White RI. The natural history of epistaxis in hereditary hemorrhagic telangiectasia. Laryngoscope 1991;101(9):977-980.

10. Porteous ME, Burn J, Proctor SJ. Hereditary haemorrhagic telangiectasia: a clinical analysis. J Med Genet 1992;29(8):527530 .

11. Halpern M, Turner AF, Citron BP. Hereditary hemorrhagic telangiectasia. A visceral angiodysplasia associated with gastrointestinal hemorrhage. Radiology 1968;90(6):1143-1149.

12. Vase P, Grove O. Gastrointestinal lesions in HHT. Gastroenterology. 1986;91(5):1079-1081.

13. Fulbright RK, Chaloupka JC, Putman CM, Sze GK, Merriam MM, Lee GK, Fayad PB, Awad IA, White RI Jr. MR of hereditary hemorrhagic telangiectasia: prevalence and spectrum of cerebrovascular malformations. AJNR Am J Neuroradiol 1998;19(3):477-484.

14. Shovlin CL, Guttmacher AE, Buscarini E, Faughnan ME, Hyland RH, Westermann CJ, Kjeldsen AD, Plauchu H. Diagnostic criteria for hereditary hemorrhagic telangiectasia (Rendu-OslerWeber syndrome). Am J Med Genet.2000;91(1):66-67.

15. Ballini A, Cantore S, De Frenza G, Foti C, Casulli C, Salini L, Rapani M, Grassi FR. Hereditary hemorrhagic telangiectasia (HHT) in dentistry: a literature review. Eur J Inflamm 2006;4(3): 139-146. 